\title{
Correlation of Serum Cholinesterase with Lipid Indices in Type 2 Diabetes Mellitus Patients in McGann Teaching Hospital, Shimoga, Karnataka, India
}

\author{
${ }^{1}$ Hemantha Kumara DS , ${ }^{2}$ Gurupadappa K
}

\begin{abstract}
Introduction: Type 2 diabetes mellitus (DM) is a cluster of conditions categorized by longstanding hyperglycemia accompanying with disturbances of carbohydrate, lipid and protein metabolism due to absolute/relative deficiency of insulin secretion and/or its action. Serum cholinesterase is an enzyme, which has been associated with diabetes, hypertension, cardio, and vascular disease and also it has a role in the metabolism of lipoproteins. Few studies showed that serum cholinesterase activity has been positively' correlated with lipid indices and blood lipoprotein levels.

Aim and objectives: To estimate serum cholinesterase levels in clinically diagnosed type $2 \mathrm{DM}$ patients and to evaluate the correlation between true cholinesterase level and lipid indices in the type II diabetes patients.
\end{abstract}

Materials and methods: Total 120 subjects were involved in this study. Out of which 60 were clinically diagnosed type II diabetes mellitus cases, and 60 were age and sex-matched healthy controls. Serum cholinesterase enzyme activity, fasting blood glucose levels and lipid profile and indices analysis done in event-eelated brain activation (ERBA) autoanalyzer. Statistical data analysis was performed by using Statistical Package for the Social Sciences (SPSS) 19.2 software.

Results: The enzyme cholinesterase activity levels raised in cases compared to healthy controls. The enzyme cholinesterase levels in cases revealed $9576 \pm 1542.78$ (IU/L) and in controls was 6783.9 \pm 798.98 (IU/L). The enzyme cholinesterase showed a positive correlation with every lipid indices namely total cholesterol, triglycerides, low-density lipoprotein-cholesterol (LDL-C), total cholesterol to high-density lipoprotein-cholesterol (HDL-C) ratio and negative correlation with HDL-C in cases as compared to healthy controls.

Conclusion: The outcome of our study showed that serum (true) cholinesterase level may assist as a budding risk assessment indicator of cardiovascular disease in type $2 \mathrm{DM}$.

Keywords: Cardiovascular disease, Fasting blood glucose, Lipid indices, Serum cholinesterase, Type 2 diabetes mellitus.

How to cite this article: Kumara HDS, Gurupadappa K. Correlation of Serum Cholinesterase with Lipid Indices in Type 2 Diabetes Mellitus Patients in McGann Teaching Hospital,

\footnotetext{
${ }^{1}$ Tutor, ${ }^{2}$ Professor and HOD

1,2Department of Biochemistry, Shimoga Institute of Medical Sciences, Shimoga, Karnataka, India

Corresponding Author: Gurupadappa K, Professor and HOD, Department of Biochemistry, Shimoga Institute of Medical Sciences, Shimoga, Karnataka, India, e-mail: drgurupadappak@yahoo.co.in
}

Shimoga, Karnataka, India. Indian J Med Biochem 2018;22(2): 153-156.

Source of support: Nil

Conflict of interest: None

\section{INTRODUCTION}

Type $2 \mathrm{DM}$ is a cluster of syndromes characterized by long-lasting hyperglycemia accompanied with disturbances of carbohydrate, fat and protein metabolism due to absolute' and/or relative' deficiency of insulin secretion' and/or its action.' Type 2 diabetes is a group of disease characterized by variable notches of insulin resistance' and/or augmented glucose formation. Insulin resistance arises when the cells develop lesser sensitive to insulin effects. ${ }^{1} \mathrm{DM}$ reasons for long time dysfunction of several organs like heart, kidneys, blood vessels and eyes. Much of this increased mortality and morbidity is due to cardiovascular complications in diabetic patients. ${ }^{2}$ Many studies have shown that diabetes is consistently accompanying with changes in blood lipids and lipoproteins, and these adaptations are of concern, because of their possible role in the etiology of the increased cardiovascular disease associated with diabetes. ${ }^{3-5}$ Among the various factors for developing increased cardiovascular risk in diabetes; the dyslipidemia is the major contributor. The common type of dyslipidemia in diabetes mellitus is considered by elevated triglycerides (TG), low levels of HDLc and an increased prevalence of small LDLc.

There are two categories of cholinesterases based on biological properties:

- Specific cholinesterase or acetylcholinesterase or true cholinesterase: It is found in the central and peripheral nervous system, muscles and erythrocytes. It is a high turnover enzyme with high affinity for acetylcholine, and with low affinity for non-choline esters. ${ }^{6}$

- Nonspecific or pseudo-cholinesterase or serum cholineesterase or butyryl-cholinesterase (BChE): The enzyme hydrolyzes both choline' and aliphatic' esters.

Serum cholinesterase is alpha glycoprotein formed in the liver. Mainly distributed in the central and peripheral nervous system and also in the liver. It has a lesser affinity 
for acetylcholine and is not suppressed by high concentrations of acetylcholine. ${ }^{6}$ The half-life of the enzyme is 12 days. ${ }^{7,8}$

The normal value of $\mathrm{BChE}$ ranges between 4,900 and 11,900 U/L. Increased activity has been observed in obesity, diabetes and dyslipidemia patients. ${ }^{9-11}$ The cholinesterase level reduces liver damage, inflammation, and malnutrition.

The present study is being taken up to find out whether there is a correlation between enzyme cholinesterase and lipid indices' in type 2 DM and its significance as a cardiovascular risk factor.

\section{MATERIALS AND METHODS}

The case-control study was conducted in Mcgann Hospital and Teaching Center attached to Shimoga Institute of Medical Sciences, Shimoga. Institutional ethical committee clearance has been taken. This is a case-control study involving 120 subjects. Sixty diagnosed type 2 DM outpatients attending McGann Hospital. The study also includes age and sex-matched 60 healthy individuals as controls. Patients with liver dysfunction, renal dysfunction, essential hypertension, neoplastic diseases and on its treatment, also, pregnant and lactating mothers were excluded from the study.

\section{Method of Analysis}

After obtaining informed consent from the patients, the clinical history was taken, and examination findings were noted down. About $5 \mathrm{~mL}$ of fasting venous blood sample was collected by venepuncture with aseptic precautions. Serum was separated by centrifugation and separated serum was used for estimation of serum cholinesterase, fasting blood glucose and lipid indices in erba biochemistry nalyzer (ERBA) autoanalyzer.

\section{Statistical Analysis}

The results were tabulated. The outcomes on continuous measurements are attained on mean \pm standard deviation (SD). The Statistical analysis of data was done by using software statistical analysis system (SAS) 9.2 software, SPSS 19.2, Static 10.1. The results or outcomes of cases and controls were contrasted by student t-test. A p-value of $<0.05$ considered significant. A p-value of $<0.0001$ considered as highly significant. Pearson's correlation among the parameters was also performed.

\section{RESULTS AND DISCUSSION}

In this study, Table 1, it was detected that the serum cholinesterase levels of cases were significantly greater than that of controls $(p<0.001)$ and also fasting blood glucose of cases were significantly greater than that of controls $(p<0.001)$. Table 2 , it was also found that when a correlational analysis was made between the serum cholinesterase and fiber Bragg grating (FBG), there was a positive correlation which was statistically significant $(\mathrm{p}<0.01)$.

Serum cholinesterase might be convoluted in the pathogenesis of type II diabetes either by amyloid fibrillary changes or by adopting some other risk factors of insulin resistance. The amyloid fibrils in pancreatic islets yield excessive superoxide radicals, peroxidation of lipids and inactivation of nitric oxide, which leads to apoptosis of $\beta$-cells. ${ }^{12}$

In this study, Table 3, it was also detected that when a correlational analysis was performed between the serum cholinesterase and lipid indices, there is a solid positive correlation with respect to total cholesterol, moderate positive correlation with LDL-C and total cholesterol to HDL-C ratio and also negative correlation with HDL-C which was statistically significant $(p<0.05)$ in overweight and obese type 2 diabetes

Table 1: Comparison of fasting blood glucose and serum cholinesterase in two groups studied

\begin{tabular}{llll}
\hline Lab parameters & Controls $($ Mean $\pm S D)$ & Cases $($ Mean $\pm S D)$ & $p$-value \\
\hline Fasting blood glucose $(\mathrm{mg} / \mathrm{dL})$ & $91.23 \pm 8.25$ & $189.16 \pm 25.78$ & $<0.001$ \\
Serum cholinesterase $(\mathrm{IU} / \mathrm{L})$ & $6783.9 \pm 798.98$ & $9576 \pm 1542.78$ & $<0.001$ \\
\hline
\end{tabular}

Table 2: Correlation between serum cholinesterase and fasting blood glucose in type 2 diabetic patients studied

\begin{tabular}{lll}
\hline & & Fasting blood g/ucose $(\mathrm{mg} / \mathrm{dL})$ \\
\hline \multirow{2}{*}{ Serum cholinesterase (IU/L) } & R score & 0.4239 \\
& p-value & 0.0091 \\
\hline
\end{tabular}

Table 3: Pearson's Correlation between cholinesterase and lipid indices in normal BMI type 2 diabetic patients studied

\begin{tabular}{|c|c|c|c|c|c|c|}
\hline & & $\begin{array}{l}\text { Total cholesterol } \\
\text { (mg/dL) }\end{array}$ & $\begin{array}{l}H D L-C \\
(m g / d L)\end{array}$ & $\begin{array}{l}L D L-C \\
(m g / d L)\end{array}$ & $\begin{array}{l}\text { Triglycerides } \\
(\mathrm{mg} / \mathrm{dL})\end{array}$ & $\begin{array}{l}\mathrm{CHO} / \mathrm{HDL}-\mathrm{C} \\
\text { ratio }\end{array}$ \\
\hline \multirow{2}{*}{ Serum cholinesterase (IU/L) } & R Score & 0.2610 & -0.3937 & 0.1877 & 0.3032 & 0.1209 \\
\hline & p-value & 0.4221 & 0.6456 & 0.6989 & 0.3117 & 0.6980 \\
\hline
\end{tabular}


Table 4: Comparison of study variables in controls and cases

\begin{tabular}{llll}
\hline Lab variables & Cases $($ Mean \pm SD) & Controls $($ Mean \pm SD) & $p$-value \\
\hline FBG $(\mathrm{mg} / \mathrm{dL})$ & $189.16 \pm 25.78$ & $91.23 \pm 8.25$ & $<0.001$ \\
Serum cholinesterase $(\mathrm{IU} / \mathrm{L})$ & $9576 \pm 1542.78$ & $6783.9 \pm 798.98$ & $<0.001$ \\
Total cholesterol $(\mathrm{mg} / \mathrm{dL})$ & $204.89 \pm 35.58$ & $141.78 \pm 38$ & $<0.001$ \\
HDL-C $(\mathrm{mg} / \mathrm{dL})$ & $39.21 \pm 10.67$ & $37.92 \pm 14.32$ & 0.468 \\
LDL-C $(\mathrm{mg} / \mathrm{dL})$ & $121.74 \pm 35.86$ & $89.24 \pm 30.09$ & $<0.001$ \\
Triglycerides $(\mathrm{mg} / \mathrm{dL})$ & $196.52 \pm 91.25$ & $120.78 \pm 35.74$ & $<0.001$ \\
CHO/HDL ratio & $5.20 \pm 3.3$ & $3.81 \pm 2.65$ & $<0.001$ \\
\hline
\end{tabular}

patients compared to normal body mass index (BMI) type 2 diabetes patients. The results of the present study are in harmony with a study done by Tomoyuki et al. ${ }^{13}$ who had reported that serum cholinesterase is strongly accompanied with adiposity formation, changes in lipid profile/indices and insulin resistance.

Several changes in carbohydrate metabolism because of diabetes lead to many biochemical changes in the metabolism of lipids and affecting the blood lipoproteins levels (Table 4). So, there is a higher level of cholesterol and triglycerides in the blood and which leads to a reduction in HDL cholesterol levels. ${ }^{14}$

The results of the present study can also be compared with a study done by Alcantra et al. ${ }^{15}$ showed that serum cholinesterase activity was positively correlated physiological factors, diabetes, and even with albumin, various lipoproteins and apoprotein B (Apo $B$ ), and even measures of overweight and obesity and hypertension.

The studies like 'serum cholinesterase in type $2 \mathrm{DM}$ : a biochemical and bioinformatics approach' by Sridhar et al. ${ }^{16}$ showed cholinesterase enzyme level was inversely related to serum cholesterol level, and Cwertnia et al. ${ }^{17}$ suggested that the positive correlation of the cholinesterase activities to diabetes mellitus and also to insulin resistance could depend on butyrylcholinesterase variant (CHE2) locus variability.

\section{CONCLUSION}

This study showed that serum cholinesterase levels raised in type $2 \mathrm{DM}$ cases which suggest that serum cholinesterase levels very much correlates with serum lipid indices in type II diabetes patients. The outcome of our study specifies that serum cholinesterase might function as a budding risk assessment indicator of cardiovascular disease in type $2 \mathrm{DM}$.

\section{LIMITATION}

Limitation of the current study is that community-based study comprising a large group of representatives is necessary to generalize serum cholinesterase as a more specific tool in type $2 \mathrm{DM}$.

\section{IMPLICATION}

Serum cholinesterase can be used as a risk assessment factor of cardiovascular disease in type $2 \mathrm{DM}$, and hence serum cholinesterase parameter can be castoff as a routine parameter for type $2 \mathrm{DM}$ patients.

\section{REFERENCES}

1. Bennett PH, Knowles WC. Definition, diagnosis and classification of diabetes mellitus and glucose homeostasis. Kahn CR, Weir GC, King GL, Jacobson AM, Moses AC, Smith RJ, editors. Joslin's Diabetes Mellitus. 14th edition. Boston: Ovid Technologies, Inc. 2005; p 331-333.

2. Park K et al. Diabetes mellitus, in park's text book of preventive and social medicine, 24rd edition. 2013;341-345.

3. Moghadam RH, Latiffah A. Investigation of lipid profiles and lipid peroxidation in patients with type 2 diabetes. European Journal of Scientific Research. 2009;28(1):6-13.

4. Howard BV. Diabetes and plasma lipoproteins in Native Americans. Studies of the Pima Indians. Diabetes Care 1993;16:284-291.

5. Beckman JS, Koppenol WH. Nitric oxide, superoxide, and peroxynitrite: the good, the bad, and ugly. American Journal of Physiology-Cell Physiology. 1996 Nov 1;271(5):C1424C1437.

6. Davis L, Britten JJ, Morgan M. Cholinesterase Its significance in anaesthetic practice. Anaesthesia. 1997 Mar;52(3):244-260.

7. Ostergaard D, Viby-Mogensen J, Hanel HK, Skovgaard LT. Half-life of plasma cholinesterase. Acta Anaesthesiol Scand. 1988:32:266-269.

8. Pan Y, Muzyka JL, Zhan CG. Model of human butyrylcholinesterase tetramer by homology modeling and dynamics simulation. J Phys Chem B. 2009;113:6543-6552.

9. Paes AM, Carniatto SR, Francisco FA, Brito NA, Mathias PC. Acetylcholinesterase activity changes on visceral organs of $\mathrm{VMH}$ lesion-induced obese rats. Int J Neurosci. 2006;116:1295-1302.

10. Cucuianu M, Nistor T, Hâncu N, Orbai P, Muscurel C, Stoian I. Serum cholinesterase activity correlates with serum insulin, Cpeptide and free fatty acids levels in patients with type 2 diabetes.Rom J Intern Med. 2002;40:43-51.

11. Kutty KM, Payne RH. Serum pseudocholinesterase and verylowdensity lipoprotein metabolism. J Clin Lab Anal. 1994;8: 247-250.

12. Johansen AE-M, Nielsen D, Andersen G, Hamid YH, Jensen DP, Glümer C, et al Large-scale studies of the functional K variant of the butyrylcholinesterase gene in relation to Type 2 diabetes and insulin secretion. Diabetologia 2004;47:1437-1441.

13. Iwasaki T, Yoneda M, Nakajima A, Terauchi Y. Serum butyrylcholinesterase is strongly associated with adiposity, the serum lipid profile and insulin resistance. Internal Medicine. 2007;46(19):1633-1639. 
14. Sniderman AD, Scantlebury T, Cianflone K. Hypertriglyceridemic hyperapoB: the unappreciated atherogenic dyslipoproteinemia in type 2 diabetes mellitus. Ann Intern Med 2001;135:447-59.

15. Alcantara VM, Chautard-Freire-Maia EA, Scartezini M, Cerci MS, Braun-Prado K, Picheth G. Butyrylcholinesterase activity and risk factors for coronary artery disease. Scandinavian journal of clinical and laboratory investigation. 2002 Jan 1;62(5):399-404.
16. Sridhar GR, Nirmala G, Apparao A, Madhavi AS, Sreelatha S, Rani JS, et al. Serum butyrylcholinesterase in type 2 diabetes mellitus: a biochemical and bioinformatics approach. Lipids in health and disease. 2005 Dec;4(1):18.

17. Cwiertnia MM, Alcântara VM, Réa RR, Faria AC, Picheth G, Scartezini $\mathrm{M}$, et al. Butyrylcholinesterase and diabetes mellitus in the CHE2 C5-and CHE2 C5+ phenotypes. Arquivos Brasileiros de Endocrinologia \& Metabologia. 2010 Feb;54(1):60-67. 